\title{
Energy-Delay-Balanced Load Dispatching in Cloud- Assisted Edge Computing of Smart City
}

\author{
Ren Zhang ( $012301910 @ q q . c o m$ ) \\ Beihang University https://orcid.org/0000-0003-1445-1032 \\ Qianhong Wu \\ Beihang University \\ Han Zhang \\ Beihang University \\ Bo Qin \\ Renmin University of China
}

\section{Research}

Keywords: Cloud Assisted Mobile Edge computing, Smart City, Energy, Delay, CAME, KKT.sample, article, author

Posted Date: January 15th, 2021

DOI: https://doi.org/10.21203/rs.3.rs-144553/v1

License: (1) (1) This work is licensed under a Creative Commons Attribution 4.0 International License. Read Full License 


\section{Abstract}

As smart city develops, Cloud Assisted Mobile Edge computing (CAME) framework is popular because it has the advantage of low delay and cost. But the computing capacity of mobile users is constrained in energy consumption, especially how to overcome the tradeoff between system latency and energy. In this article, an energy-delay-balanced load dispatching algorithm is suggested by exploiting the Karush-KuhnTucker (KKT) conditions. Its exponential complexity is circumvented by taking the advantage of the linear property of constraints, rather than directly figuring out the KKT conditions. Compared to the fair ratio algorithm and the greedy algorithm, our suggested one is proved to provide better performance by simulation, which can decrease the delay by $35 \%$ and $49 \%$ respectively on the basis of the same energy consumption. The results indicate that the designed algorithm provides desirable tradeoff between system latency and energy.

\section{Full Text}

This preprint is available for download as a PDF.

\section{Figures}




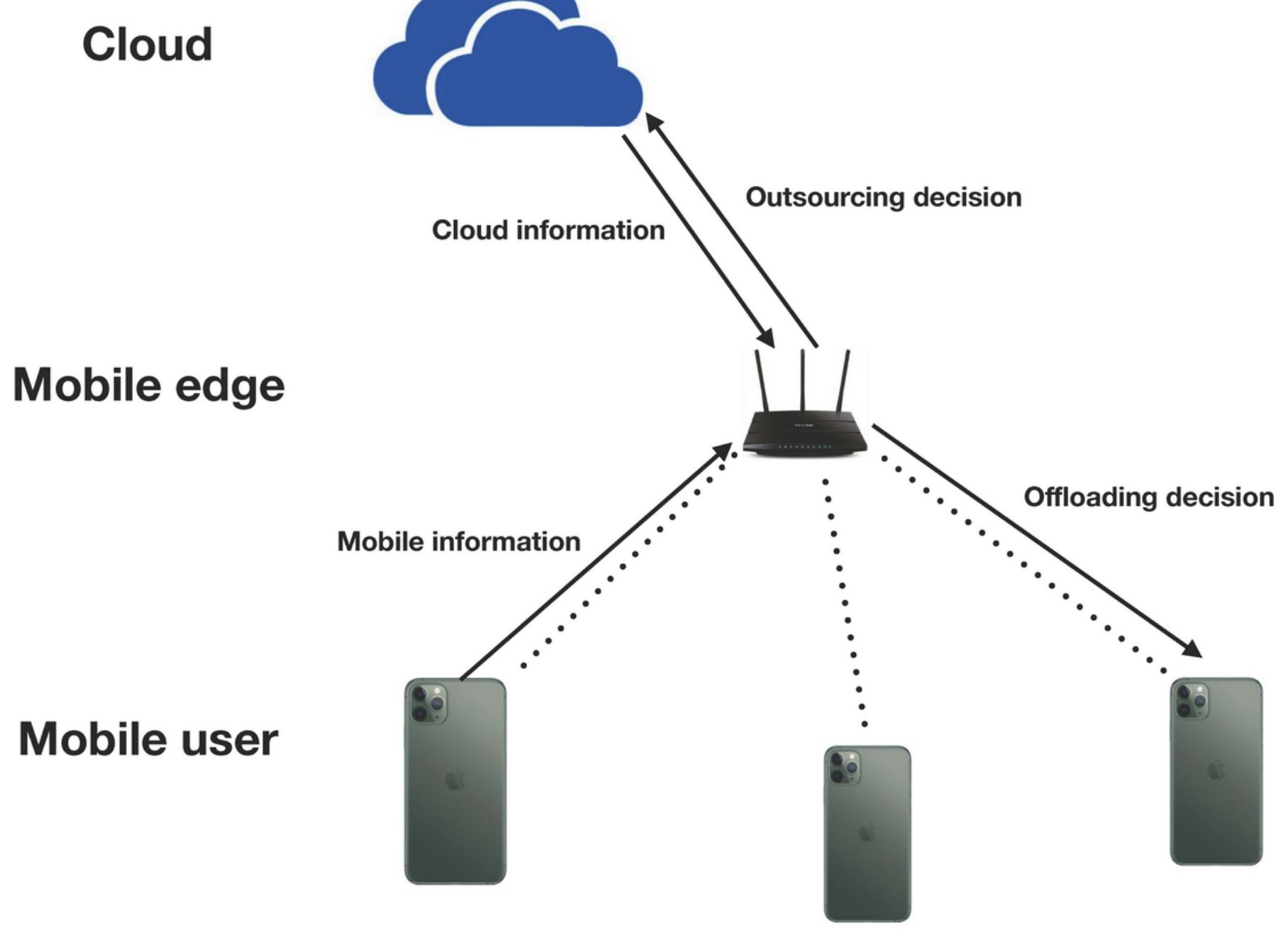

Figure 1

CAME framework 


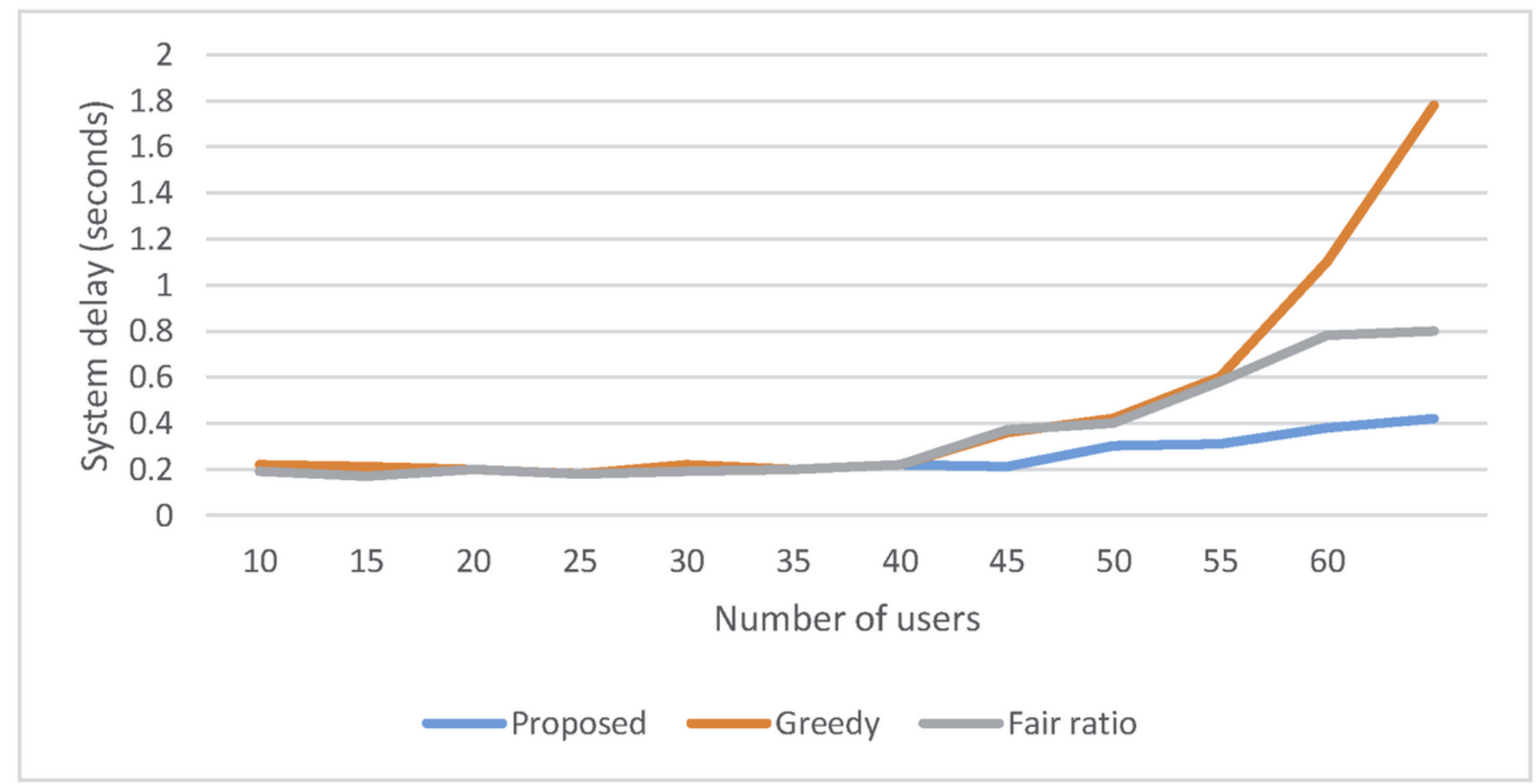

Figure 2

System delay of different algorithms

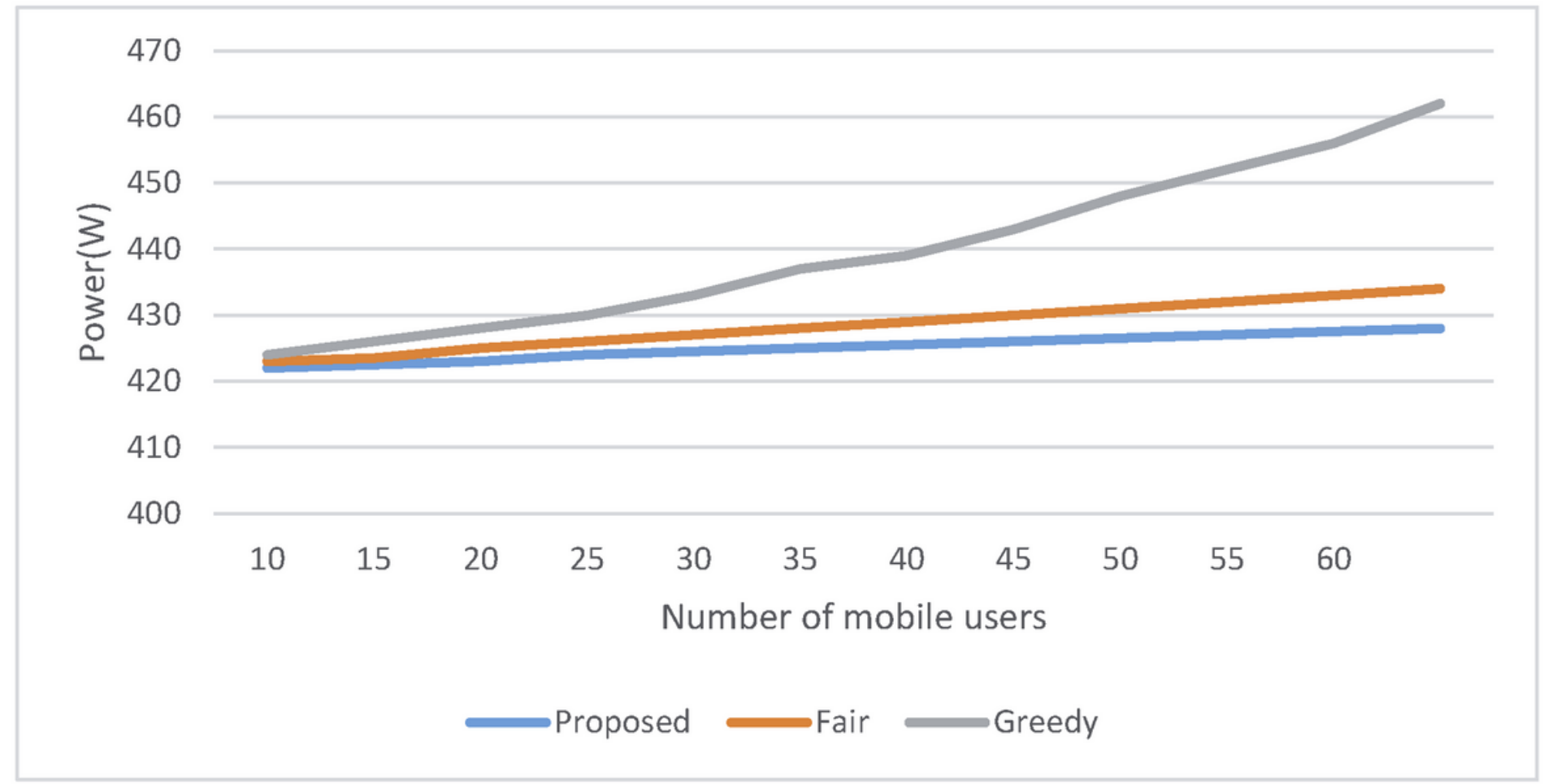

Figure 3 
System energy consumption of different algorithms

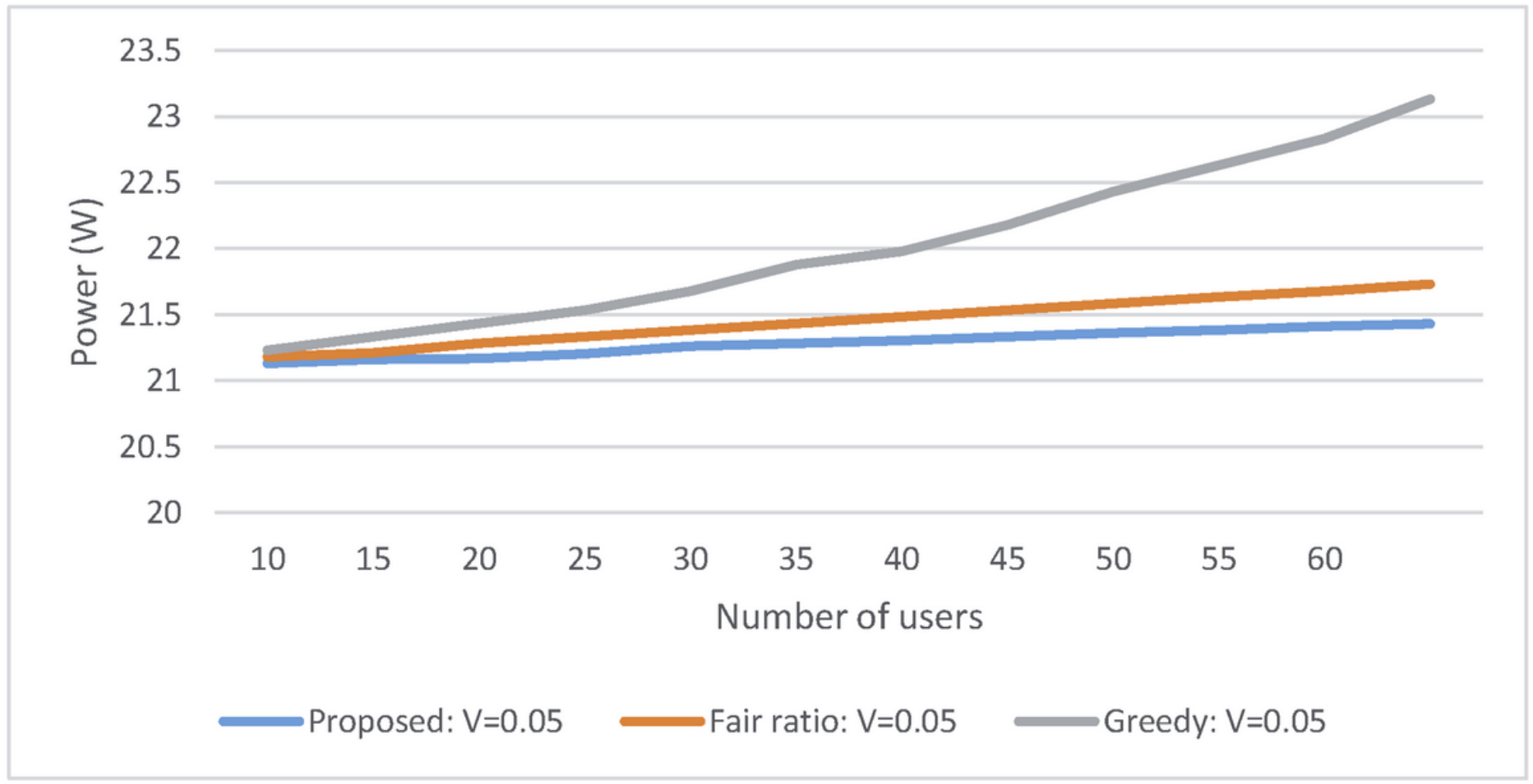

\section{Figure 4}

System energy consumption over weight constant $v=0.05$

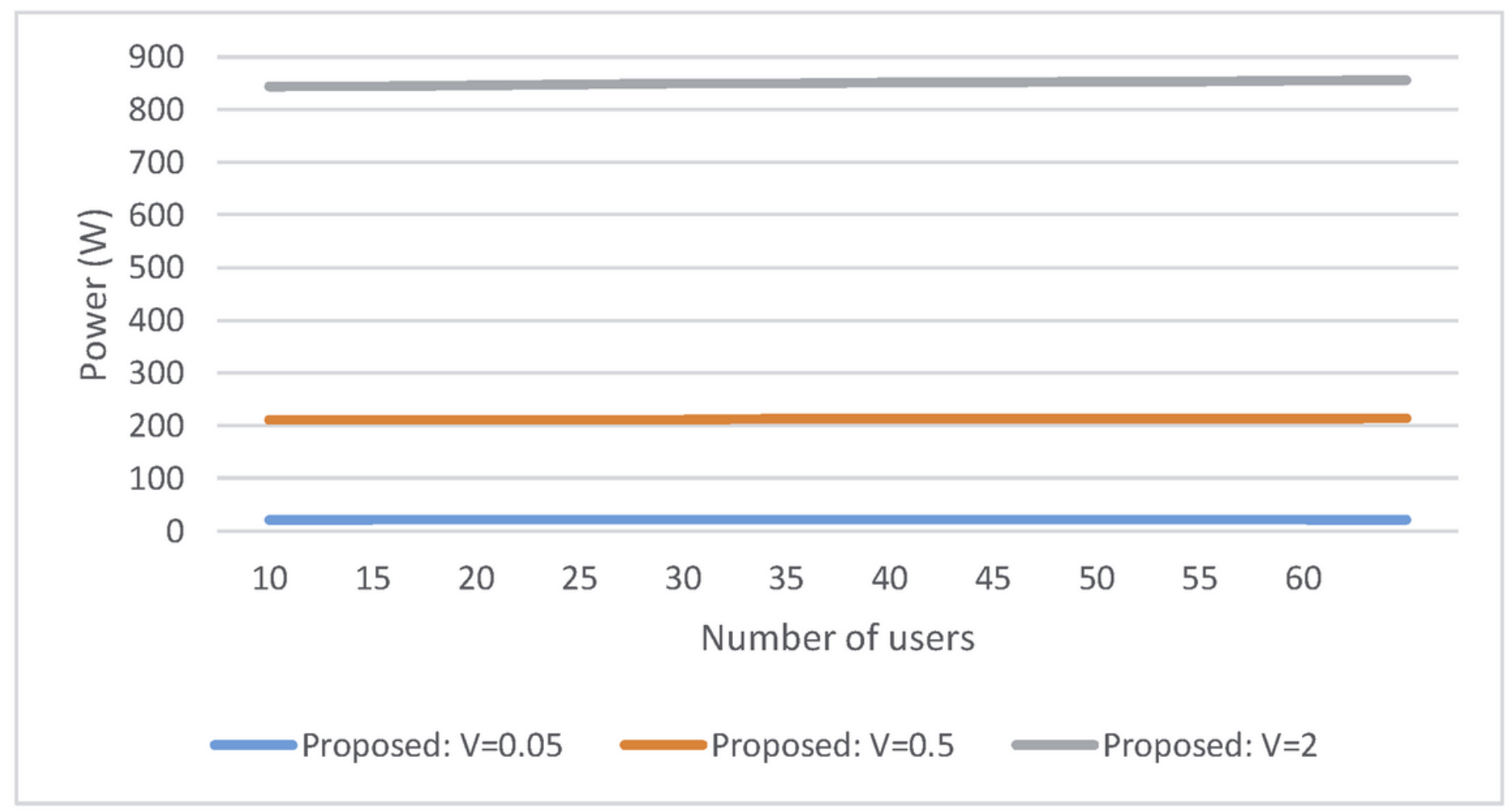


Figure 5

System energy consumption over different weight constants

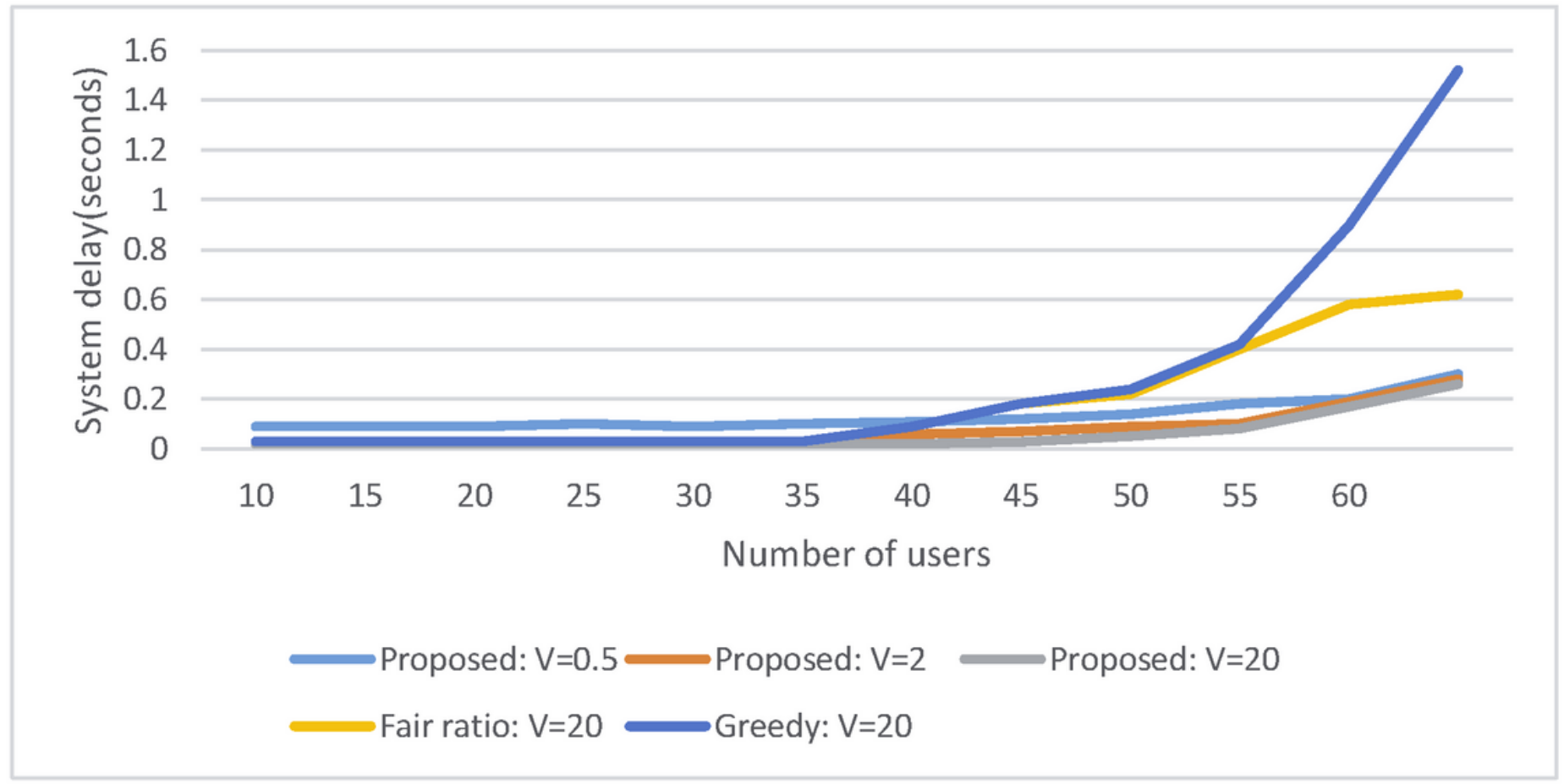

\section{Figure 6}

System delay over weight constants

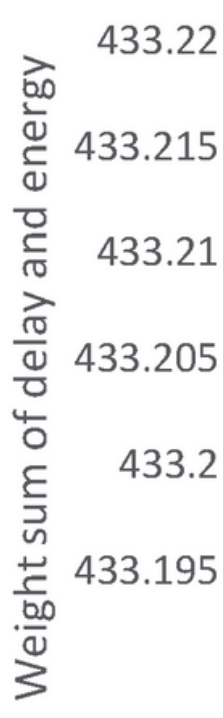

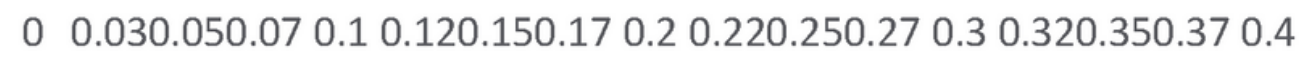

Variance of mobile serving rates

Wair ratio:1.0 $=$ Fair ratio:0.9 Fair ratio:0.95 $=$ Fair ratio:0.8 
Figure 7

System performance with heterogeneous users in the fair ratio algorithm

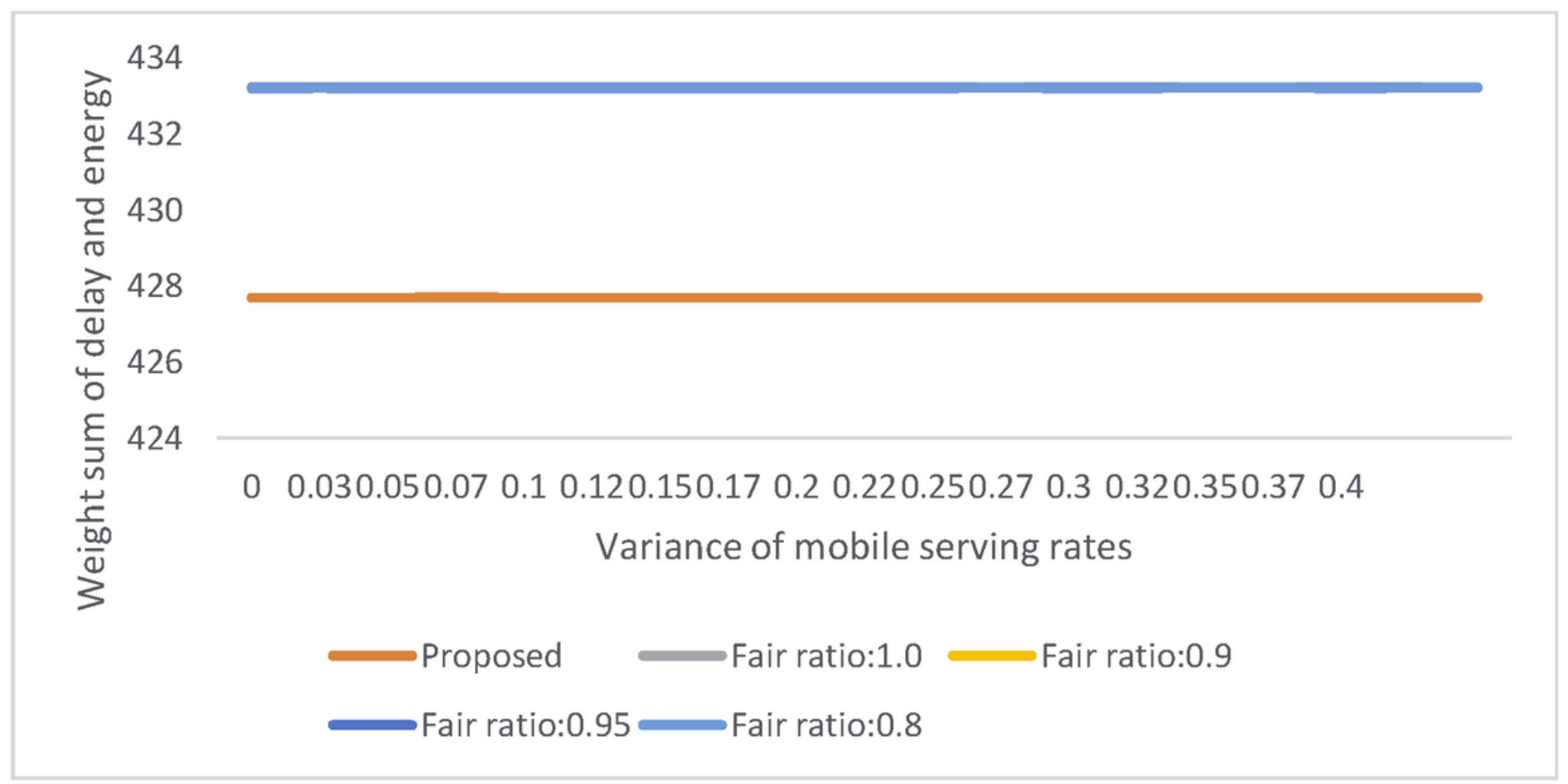

\section{Figure 8}

System performance with heterogeneous users in two algorithms

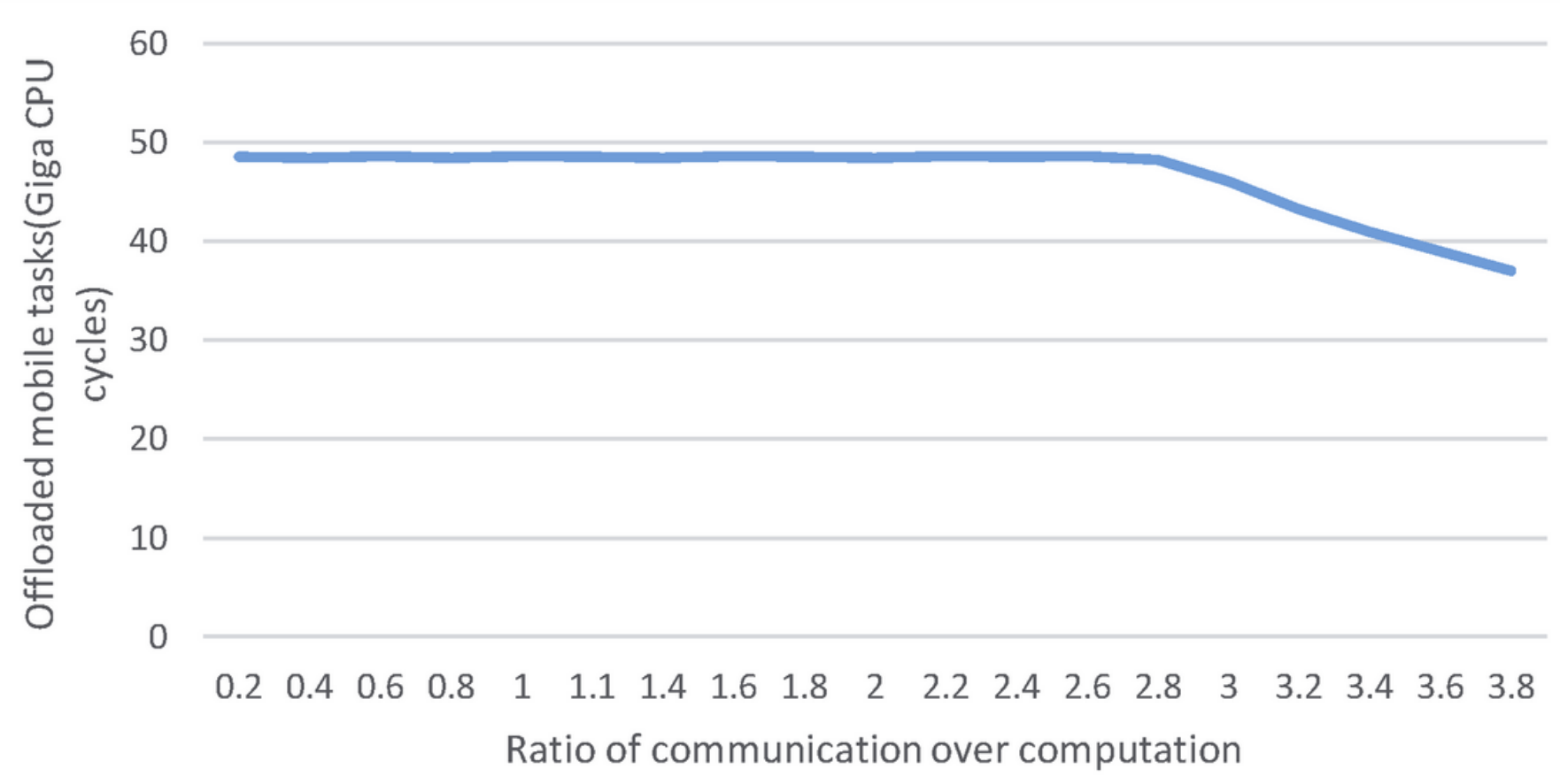


Figure 9

o\oad workloads with c

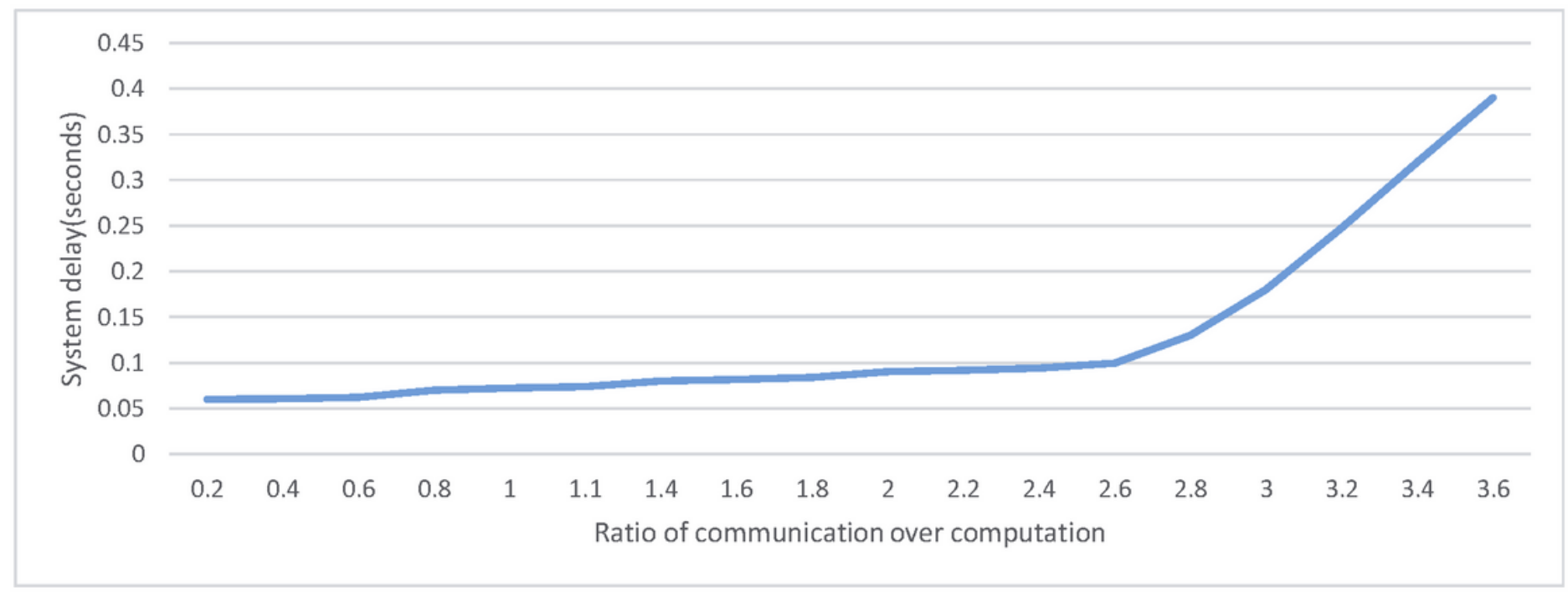

Figure 10

System delay with c 